\title{
OCGLUSION OF THE HEPATIC VEINS WITH CIRRHOSIS OF THE LIVER
}

BY

\author{
ROBERT HUTCHISON, M.D., F.R.C.P., \\ Physician to the London Hospital, and to the Hospital for Sick Children, \\ Great Ormond Street, \\ and \\ S. LEVY SIMPSON, M.D., M.R.C.P., \\ Medical First Assistant, London Hospital.
}

The case described below is of interest, not only because of its rarity, but also because the patient had been observed over a large number of years. Primary carcinoma of the liver finally supervened, and the absence of ascites throughout the illness was also an unusual feature. The autopsy findings, and the pathological fact that occlusion of the hepatic veins rarely if ever occurs in a non-syphilitic cirrhosis, have led us to present the case as one of primary occlusion of the hepatic veins, with secondary fibrosis of the liver.

\section{Clinical report.}

The clinical records of this case extend over the years 1906 to 1929.

The patient, Herbert B., first came under observation in the year 1906, being then 5 years of age. He was one of a large family, and there was no clinical reason to suspect a syphilitic taint, but of course these were the pre-Wassermann days. The abdomen was said to have been very protuberant since he was a year old, and when first seen the liver was enlarged down to the umbilicus, and smooth and firm to palpation. The spleen at that time was not felt. There was no jaundice nor ascites, and though not a robust boy he presented no other signs of disease. No diagnosis was arrived at.

Two years later (1907) the notes show that the liver was 'becoming irregular' and in the following year it is stated that 'the edge of the liver is now two finger-breadths above the umbilicus and the spleen can be felt one finger-breadth below the costal margin.' By 1910 the condition was unchanged and in 1912 , the patient being then 11 years old, it was noted that ' the liver is the same and the spleen can just be felt.' His general health continued fair. There is no note of his condition after this until 1920, when the liver was only about one fingerbreadth below the ribs and was 'rather firm'; the spleen could not be felt.

He was then lost sight of till September, 1929. He had now reached the age of 28 and complained of severe attacks of epigastric pain which had recently begun to trouble him along with some decline in his general health. Examination showed him to be a man of rather poor physique, thin and pallid, but with none of the 'cirrhotic facies,' no icterus, nor clubbing of the fingers. There were no stigmata of congenital syphilis. The liver could be felt about two finger-breadths below the edge of the ribs, it was hard and irregular, and apparently projecting from it in the epigastrium one could easily make out three rounded masses each about the size of a walnut. There was no ascites and the spleen could not be felt. The Wassermann test was negative and his other organs normal. 
At the end of September, 1929, the abdomen was explored by Mr. A. J. Walton at the London Hospital who has kindly supplied the following note :-

'A considerable amount of clear serous fluid was found in the abdomen. The liver was somewhat enlarged generally with a coarsely irregular surface on which were several dilated veins, especially in the region of the falciform ligament. The liver substance was uniformly hard. Lying between the lower border of the liver and the transverse colon were three large rounded masses more or less sharply defined but involving the omentum, which was turned up over the colon. The liver, these masses, and the colon formed an arch under the tunnel of which the stomach and duodenum ran. The great omentum was divided from the transverse colon, which was allowed to drop into its place. The three masses (which were extremely vascular, were each about 2 in. in diameter and formed of friable material), could now be lifted up. The stomach and duodenum were quite free from the growths, which were firmly adherent to and originated from the free edge of the liver above. No secondaries could be found elsewhere in the peritoneum. The rest of the liver seemed to be free ; all the nodules in this organ appearing to the naked eye to be due to the cirrhosis and not to growth. The spleen was of normal size, although slightly firmer than normal. The area of attachment of the masses to the free edge of the liver was about 2 in. The liver was firmly held on either side and a wedge, to which the masses were attached, was excised much in the way that a slice of cake is removed. The two cut edges of the liver were then sutured together with thick catgut. There was no difficulty whatever in this owing to the firmness of the liver substance. One of the rounded masses was cut into and was found to consist of very soft friable material, almost certainly carcinomatous.'

The patient died four days after operation.

\section{Pathological report.}

Professor Turnbull has kindly provided the following report on the postmortem examination made on this case.

Summary of necropsy.-General sero-fibrinous peritonitis. Operation: laparotomy and excision of primary carcinoma of liver. Typical and atypical, adenomatous and carcinomatous, regeneration of liver. Reticular fibrosis of liver. Anastomosis through capsule between hepatic veins within liver and veins of diaphragm. Occlusion of ostia of hepatic veins opening into inferior vena cava.

Thick layers of fibrin, enclosing four ounces of sero-fibrinous exudate, upon upper surface of left lobe of liver and adjacent diaphragm; fibrinous adhesions and a few drachms of pus throughout remainder of abdominal cavity. Sero-fibrinous pleurisy $(2 \mathrm{oz}$.) over lower lobe of left lung. Enlargement and slight fibrosis of spleen. Edema and parenchymatous degeneration of kidneys. Congestion and mucous catarrh of stomach. Great dilatation of duodenum (circumference $=13 \mathrm{~cm}$.) and upper jejunum (circumference $=15 \mathrm{~cm}$.). Acid digestion of lungs. (Edema and parenchymatous degeneration of myocardium. Edema of brain. Slight atheroma of thoracic and abdominal aorta. Thymus partly adipose. Red hæmatogenous marrow in neck and upper $7 \mathrm{~cm}$. of shaft of femur.

Weights.-Body =99 lb. 10 oz. (45.1 kgrm.); liver =4 lb. $5 \frac{1}{2}$ oz. (1970.3 grm.); heart $=8$ oz. $(226 \cdot 8$ grm. $)$; kidneys $=10 \frac{3}{4}$ oz. $(304 \cdot 7$ grm. $)$; spleen $=7 \frac{3}{4}$ oz. $(219 \cdot 7$ grm. $)$; brain $=3$ lb. $0 \frac{3}{4}$ oz. $(1382.0$ grm. $)$; suprarenal bodies, $=17 \cdot 1$ grm.; pituitary, $=0.5$ grm.; thyroid, $=15.9$ grm. ; thymus, $=3.9$ grm.; pancreas, $=53.4$ grm. ; bodies of testes, $=25.8 \mathrm{grm}$.

The length of the body was $5 \mathrm{ft} .4 \mathrm{in}$. (1.63 metre).

Macroscopical examination.-The liver was enlarged, and the outer surface coarsely nodular; the nodules measured up to $2 \mathrm{~cm}$. in diameter. The cut surface showed scattered, stellate areas (cores up to $0.5 \mathrm{~cm}$. in diameter) of grey or pink fibrous tissue, from which radiated trabeculæ of similar fibrous tissue. Between these stouter trabeculæ a net of very delicate sunken, grey trabeculæ separated subangular and rounded areas of moist, brown parenchyma of from 2 to $5 \mathrm{~mm}$. in diameter. A large wedge-shaped area, with its base $(5 \mathrm{~cm}$. from side to side) at the hilum and its apex $(4 \mathrm{~cm}$. from side to side) passing vertically down the anterior surface of the right lobe, and numerous small areas immediately beneath the capsule were sunken and showed pin-head nodules of parenchyma, each with a portal system in the centre, lying close together in a sunken ground of partly blood-red, partly grey fibrous tissue. 
A nodule $(0.4 \mathrm{~cm}$. diam.) of firm yellow tissue raised the capsule on the anterior surface of the left lobe, and a similar nodule $(0 \cdot 2 \mathrm{~cm}$. diam.) lay a little distance beneath it. Slightly above its centre the postero-lateral margin of the right lobe was occupied for $6 \mathrm{~cm}$. by raised, pure white nodules. Section showed this to be the base of a wedge of firm, greyish white tissue, closely beset with opaque yellow areas of necrosis, which extended inwards like a wedge for $3 \cdot 5 \mathrm{~cm}$. Immediately beyond the apex a large portal vein was distended by similar white tissue.

Four centimetres to the left of the round ligament was a vertical, sutured incision $5 \mathrm{~cm}$. long. On section the incision lay in the centre of an area, $6 \mathrm{~cm}$. in width, of opaque yellow necrosis. The portion of tissue removed by this incision had been received previously from the operating theatre. It consisted of a nodule $(6 \times 6 \times 5 \cdot 5 \mathrm{~cm}$.) in a portion of omentum adherent to a segment $(7 \times 6 \cdot 6 \times 5 \mathrm{~cm}$.) of liver. Along the line of excision of the segment of liver was a zone, $2 \mathrm{~cm}$. wide, of fibrotic, brown hepatic tissue similar to that of the liver at necropsy. Within the zone were two rounded areas of white tissue, $1 \mathrm{~cm}$. and $0.6 \mathrm{~cm}$. in diameter. The rest of the liver, beneath the serous surface, was occupied by a hard mass. This showed a large central area of sunken dense grey fibrous tissue. From this fibrous strands passed radially to cut the surrounding tissue into lobules about $2.5 \mathrm{~cm}$. in diameter. These lobules were subdivided by more delicate fibrous strands. The lobules consisted of firm tissue which was either grass-green or pale creamy brown. A line of fibrous tissue separated this mass from the zone of brown hepatic tissue. The mass in the adherent omentum consisted of soft, friable white tissue divided by indistinct trabeculæ into round lobules of a diameter of $0 \cdot 8 \mathrm{~cm}$.

The hepatic veins in the substance of the liver were abnormally wide and thick. The hepatic portion of the inferior vena cava was slightly narrowed $(3 \mathrm{~cm}$. in circumference) at the upper border of the liver, a raised ridge $(1 \mathrm{~mm}$. high) crossing its anterior surface and forking on the left. In this ridge there were a few venous orifices too minute to admit a probe. Opposite the right extremity of the ridge a strand of fibrosis $(0.5 \mathrm{~cm}$. wide) extended into the substance of the liver for one centimetre to end against the apparently blind extremity of a dilated (lumen, $0 \cdot 5 \times 0.3 \mathrm{~cm}$.) hepatic vein. This vein after a short course gave off a descending branch and then passed, with no appreciable diminution of its lumen, to the junction of the middle and outer thirds of the superior surface of the right lobe, where it pierced the capsule and joined a group of large, wide (widest diameter, $1 \mathrm{~cm}$.) veins on the lower and upper surfaces of the diaphragm. In the inferior vena cava, $1 \cdot 3 \mathrm{~cm}$. above the left extremity of the ridge, was a faint scar. Beneath this, with its base against the vein, was a triangular area $(0.5 \times 0.5 \mathrm{~cm}$. $)$ of fibrosis in the substance of the liver. The apex met the apparently blind extremity of a dilated $(0 \cdot 4 \mathrm{~cm}$.) hepatic vein. This vein after a short course gave off a descending branch, and then passed horizontally across the liver to the left border, where, piercing the capsule, it passed, now $1.2 \mathrm{~cm}$. in diameter, to the dilated diaphragmatic veins.

From a group of three openings (widest $0.5 \times 0.1 \mathrm{~cm}.), 1.4 \mathrm{~cm}$. above the right extremity of the ridge, one vein passed within Glisson's capsule to the front of the superior angle of the right lobe, and others passed into the diaphragmatic veins. Another orifice $(1 \cdot 3 \times 0 \cdot 6 \mathrm{~cm}$.) in the inferior vena cava, $1 \cdot 3 \mathrm{~cm}$. above the left extremity of the ridge, led into a wide vein ( $2 \mathrm{~cm}$. in circumference) on the inferior surface of the left dome of the diaphragm.

No trace could be found of the ductus arteriosus. The portal veins, bile ducts and gallbladder were normal.

Microscopical examination. Liver.-Portions of tissue for both embedding in paraffin and cutting on the freezing microtome for Herxheimer's method were taken from six portions of the liver that were free from carcinoma and showed variations in pattern to the naked eye.

All portions showed a reticular, the so-called portal, fibrosis: a network of fibrous trabeculæ of various breadths enclosed pseudolobules of various sizes. Most of the trabeculæ consisted of dense collagenous tissue which contained stout elastic fibres and was free from infiltration with round cells. The large stellate areas of fibrosis were found most frequently beneath the capsule. In these and the broader trabeculæ many portal systems lay close together ; between them was a closely meshed net of broad bands of stout collagenous and elastic fibres; most of the meshes contained blood spaces, others contained pseudobile canaliculi, or, rarely, hepatic cells showing fatty degeneration. The narrower trabeculæ contained and united 
both portal systems and sublobular or larger hepatic veins. A portal vein filled with granulation tissue was found in a trabecula. Trabeculæ formed by fibrosis round hepatic veins most frequently formed the boundaries of the pseudolobules, whilst the portal systems more often iay free in the pseudolobules or projected as spurs from the boundaries. Trabeculæ containing hepatic veins also projected as spurs into the pseudolobules. In addition, particularly in a section from a sunken area in the $1 \mathrm{eft}$ lobe, an exrly stage of granulation was seen within pseudolobules. About central and sublobular veins, and uniting central veins to one another and to sublobular veins, were areas in which a net of ba:ds of delicate collagenous fibrils, without elastic fibrils, contained in its meshes engorged sinusoids and numerous mononuclear leucocytes, large lymphocytes, small lymphocytes and cells loader with fat and lipochrome. Most of the fatty cells were macrophages; others were neutrophil leucocytes, and hepatic cells ; the fatty hepatic cells were confined to the periphery of the areas. The fat was almost entirely isotropic.

The pseudolobules varied greatly in size. The smaller were bounded by venous trabeculæ and contained one or more portal systems. The larger contained both portal systems and hepatic veins. The amount of hepatic parenchyma within the pseudolobules was greatly in excess of the normal; the normal relation of the enclosed portal veins to the central or sublobular veins was much disturbed; the radial arrangement of the columns was lost, the columns tending to be arranged concentrically in rounded masses at the sides of portal systems. The walls of the central and sublobular veins were thickened. The hepatic cells round them were fatt 5 . and the columns were narrow or were replaced by a few rounded, dissociated cells. This degeneration and loss of cells round the hepatic veins was associated with a thickening and multiplication of the interstitial collagenous fibrils.

The yellow nodule beneath the capsule of the left lobe was found to be a pseudolobule of atypical constitution. It contained three portal systems. Except at the right and left margins the hepatic cells were considerably larger than in other pseudolobules, and had much larger nuclei and a slightly more basophil cytoplasm. They frequently formed columns many cells thick, and occasionally enclosed a lumen. They were polygonal. The nuclei varied considerably in size and in depth of stain; very large nuclei, multiple nuclei and karyokinetic figures were numerous. In the periphery at the two spots mentioned above, the columns of abnormal cells were directly continuous with columns similar to those in ordinary pseudolobules. On one side these ordinary columns were narrowed and pressed together concentrically round the mass of abnormal cells.

Microscopic examination was made of four pieces of the portion of liver removed from the left lobe by operation and one piece of the white mass found in the right lobe at necropsy. The sections included the two isolated nodules seen in the portion of liver removed at necropsy. The green and white growth was separated from the fibrotic liver of ordinary appearance by a fibrous capsule. In most of this capsule elastic fibres were sparse and delicate ; in places the capsule was of the same constitution as the fibro-elastic trabeculæ in the liver, or such trabeculæ were included within it. The growth was divided into lobules by trabeculæ, some of which resembled those in the fibrotic liver, while others were broader and contained only a few elastic fibrils. Within the trabeculæ and septa many portal veins were filled with vascularized granulation or fibrous tissue. Some of the lobules were much larger than the pseudolobules in the fibrotic liver. One large lobule consisted of polygonal cells packed in a mass within which were a few branching capillary clefts. The clefts were bounded by a collagenous membrane, and their lumen was usually wide. The cells were of the size of normal hepatic cells or slightly smaller; their nuclei were very constant in size and structure, and resembled those of normal hepatic cells ; their cytoplasm was usually as vacuolated as that of hepatic cells filled with glycogen.

In the other lobules the cells varied greatly in size but most were much larger than normal liver cells. They were arranged between capillaries either in solid columns or as tubes. Luminal spaces also lay within solid columns. The number of capillaries varied in different places, but they usually formed a net which divided the cells into elongated oval columns from two to twelve cells wide, or into tubules. The cells in the periphery of the solid columns were cubical or columnar, and those in the centre were polygonal. The cells that formed the well of tubules or lined luminal spaces within solid columns were usually tall, columnar but sometimes cubical. The number of tubules and luminal spaces varied in different places. The cytoplasm of the 
cells was more basophil than that of normal hepatic cells. It was usually granular and vesicular. Vesiculation was frequently very conspicuous. Many cells were loaded with doubly refractile lipoid, but this did not account for all the vesiculation. The nuclei varied greatly in size and depth of stain. They were usually large, and many were very large. Multiple nuclei and karyokinetic figures were numerous. Similar cells sometimes filled lymphatic capillaries in the septa. In the mass from the right lobe there were large areas of dissociation and necrosis of the cells, often accompanied by hæmorrhage. The tubular lumina contained coagulated albumin, bile-stained albumin or bile, and also, frequently, a few round, fatty cells. Occasionally the luminal spaces were very wide. Wide capillary spaces were also present.

Omentum.-In the omentum the growth was again lobulated, and the interlobular septa contained few or no elastic fibres. In general there were fewer capillaries, so that the cells were divided into larger masses. There were some very wide capillary lakes. Lumina were also fewer ; they again contained a bile-stained exudate. Many cells were loaded with doubly refractile lipoid. There were a few areas of hæmorrhage and dissociation and necrosis of the cells.

Hepatic ostia.-Selected sections were stained from a series taken from both sides of a cut through the blind extremity of the large right hepatic vein and the fibrous band which united it to the vena cava. The hepatic vein had a very thick media of large muscle fibres embedded in dense collagenous tissue, a narrow adventitia of collagenous and elastic fibres, and an intima of small muscle fibres and numerous delicate elastic and collagenous fibrils. Towards the vena cava it communicated with a venous sinus, whose relatively narrow wall consisted of a continuation of the intima and of a narrow prolongation of the media and adventitia, represented only by elastic and collagen fibres containing very few small muscle cells. Several veins with similar walls communicated with this sinus, and one could be traced to the adventitia of the inferior vena cava. This vein was filled with vascularized fibrous tissue containing numerous stout elastic fibres. Many other veins in the sections were filled with similar canalized dense fibro-elastic tissue. Other veins were filled with a younger granulation tissue free from elastic, and others with recent thrombus. The large hepatic vein lay within a large area, and the sinus was bordered by a zone of dense fibro-elastic tissue containing pseudobile canaliculi and groups of hepatic cells ; this tissue was part of a network of dense fibrosis similar to that in the rest of the liver.

The only vein traced into the lumen of the inferior vena cava was a relatively small one. The mouth of the funnel formed by the vena cava at the orifice was filled, and constricted, by a mass of vascularized dense collagenous and elastic tissue, whose fibres were orientated differently from those of the intima with which they merge. The vein opened through a canal in this plug.

Interpretation of changes. ORIGIN OF THE CANCER.-The structure of almost all the pseudolobules is characteristic of an ordinary, typical regeneration of hepatic columns. In the yellow subcapsular nodule the greater part of a pseudolobule is occupied by cells which are atypical in appearance, frequently form columns of more than a double row of cells, and occasionally surround a lumen. These cells appear to have arisen in situ, because the columns in which they lie merge into columns of ordinary appearance. The pseudolobule appears to b9 the site of an atypical regeneration. The mass of white growth in the right border of the liver is probably a cancerous metastasis from the mass in the left lobe. It is of wedge-shape, and a portal vein at the apex of the wedge is filled with growth. In structure it resembles closely the mass in the left lobe, but forms smaller lobules in a more abundant stroma and is more necrotic. The mass in the left lobe is undoubtedly cancerous because it has extended into the omentum. That the cancer arose primarily in the liver could be recognized with certainty even before the necropsy, because the cells in places form tubu'es containing bile pigment. In one large lobule the cells and their nuclei are very constant in size and structure, and resemble closely normal liver cells loaded with glycogen or with glycogen and fat. This lobule is atypical in that capillary spaces are scanty, but from the character of the cells it appears histologically to be adenomatous rather than carcinomatous. The other lobules are composed of liver cells so atypical that cancer would have been indicated histologically even if infiltration. of lymphatics and of the omentum had not been found. There is no direct evidence that thi: adenomatous and cancerous growth arose by atypical regeneration in pseudolobules. The 
growth is arranged in lobules which are similar to the pseudolobules. But the trabeculæ bounding these lobules are for the most part composed of a fibrous tissue which contains few or no elastic fibres. Most of the trabeculæ are evidently of much more recent formation than the trabeculæ bounding the pseudolobules, and represent an interstitial reaction to the cancer. In view, however, of the regeneration throughout the liver and the atypical regeneration in the subcapsular pseudolobule there can be no doubt that the cancer originated in regeneration.

The cancer in the omentum is slightly more atypical than in the liver, capillaries being more scanty and columnar structure being in consequence less definite. Bile pigment is, however, still formed by the cells.

NATURE OF THE FIBRosis.-In all sections there is evidence of ' back-pressure atrophy, that is to say, of fatty degeneration and necrosis of the hepatic cells round central and sublobular hepatic veins. The cells nearer the portal systems, and therefore nearer the oxygenated blood, are healthy. In some areas this degeneration and necrosis is conspicuous, and cellular infiltration and early fibrosis involve all the cells except those grouped round the portal systems. There is here an early fibrosis which is doubtless due to the interference with the circulation. But most of the fibrous trabeculæ forming the reticular fibrosis throughout the liver are much older : they consist of stout collagenous fibres and numerous stout elastic fibres, and are free from cellular infiltration. The larger stellate fibrotic areas from which trabeculæ radiate are of similar age. These fikrotic areas and the stoutest trabeculæ have been formed by complete necrosis and fibrosis of whole lobules. The other trabeculæ have been formed by necrosis and fibrosis round hepatic veins and by fibrous elongation of portal sheaths. The resulting fibrous reticulum is not definitely due to ' back pressure.' In a reserved section from another case of occlusion of the hepatic orifices which shows undoubted 'back pressure' fibrosis, the fibrous tissue forms a small meshed net with a portal system in the centre of each mesh. In this section, however, the fibrosis is younger than in the present case, and regeneration is less. The old fibrosis in the present case resembles that of an ordinary, so-called portal, fibrosis. Nevertheless it could undoubtedly have arisen in necrosis due to interference with the blood supply. It appears, however, to be impossible to exclude a fibrosis due to toxins. Toxins attack first the cells farthest from the portal systems, that is farthest from the oxygenated blood. The cells round the central veins first degenerate and die ; the degeneration and death then extend from centre to centre of the lobules at the points farthest from the portal systems. Granulation tissue and, ultimately, dense fibrous tissue replace the necrosed areas; at the same time there is infiltration and fibroblastic proliferation in the portal systems; the undamaged hepatic cells round the portal systems undergo proliferative regeneration. The ultimate picture is that of a typical so-called portal fibrosis. This sequence of changes can be followed in trinitrotoluene poisoning (Turnbull), and in my opinion they have taken place in almost every form of so.called portal fibrosis. In as much as toxins destroy exactly the same portions of the liver as interference with the supply of oxygen does, it appears impossible to determine in this case whether the initial fibrosis was due to toxins or whether it was due to occlusion of the hepatic orifices. The recent fibrosis in the present case is certainly due to interference with the circulation, and this is perhaps in favour of a similar origin for the old.

Nature of occlusion of Hepatic orifices.-The serial sections examined failed to show the junction of the large right hepatic vein with the inferior vena cava. The sinus with which it was connected was evidently only an entering branch. Many veins in the sections are filled with old vascularized tissue. They have been occluded either by inflammation (endophlebitis) or organization of thrombus (thrombophlebitis). Endophlebitis of large veins is very rarely, if ever, found in fibrosis of the liver other than syphilitic. In syphilitic fibrosis endophlebitis and endarteritis are often conspicuous, and the distribution of the fibrosis depends essentially upon the distribution of the endophlebitis or endarteritis. This was not the case in this liver. Occlusion of veins was seldom recognizable in this liver except in the fibrous tissue about the carcinoma and close to the inferior vena cava; there was no endarteritis. Close to the obstructed orifices in the inferior vena cava stagnation of blood and thrombosis would be very likely to occur. The sections actually showed recent venous thrombosis and obstruction of veins by granulation tissue in this region in addition to the old sclerotic canalized occlusions. There can be little doubt that the old occlusion was, like the recent, due to organization of thrombi, that is, to thrombophlebitis. 


\begin{abstract}
Although the large hepatic vein was not traced to the inferior vena cava, one smaller vein was so traced. The mouth of the funnel formed by the wall of the vena cava at the orifice of this vein was filled by a vascularized plug of stout collagenous and elastic fibres ; the vein com. municated with a canal which passed through this. This plug or bridge was similar to those described and figured by Thompson and Turnbull ${ }^{13}$, and as in those casesfound its only reasonable explanation in the organization of a thrombus. Recent bracket-like thrombi at orifices are described and illustrated in the same paper. In another orifice in the inferior vena cava in the present case was a plug of fibro-elastic tissue which projected into the lumen of the vena cava like a plug of cotton wool from a test-tube. Unfortunately this orifice and its connections could not be traced farther in the series stained. That it was a plug of organized thrombus cannot be doubted.

Such evidence as has been obtained points to the ostia of the hepatic veins having been occluded by organized thrombus a long time before death. It is not possible to distinguish between the ages of this organization and of the older fibrous trabeculæ in the liver : both have reached too late a stage. The relation of the fibrosis to the occlusion has already been discussed. It might be added here that if occlusion of the hepatic orifices is a complication of non-syphilitic fibrosis of the liver, it is a very exceptional complication (H.M.T.).
\end{abstract}

\title{
History of the condition.
}

The first case of occlusion of the hepatic veins was described by Budd ${ }^{1}$ in 1857 , but the condition was not established as a separate entity until the researches of Chiari $^{2}$ were published in 1899. This author reviewed seven cases that were described prior to his own, and concluded that in all of them the obliterating phlebitis of the larger hepatic veins was interpreted as evidence of a process of contiguity and as arising from inflammatory processes in the vicinity of the veins. Chiari, however, described three cases of primary obliterating phlebitis of the hepatic veins, all in adults, in which the stenosis or obliteration was due to a thickening of the intima and was quite independent of changes in the surrounding tissue. This primary occlusion was considered by Chiari to be a disease sui generis, and in acknowledgement of his work the disease is sometimes named after him. He comments on the significance of his cases as follows :-

These three cases of obliterating phlebitis of the hepatic veins have much in common. In all there was inflammation in the wall of the veins, which, with the exception of the first cases, affected exclusively the intima; even in the first case the adventitia was affected to a very much less extent. The process therefore represented an endophlebitis. The phlebitis was localized in all three cases in the same manner, i.e., in the proximal end of the hepatic vein, although in the third case there was some peripheral extension. There was always a definite tendency to obliteration, and in many cases complete obliteration. In every case it was an entirely independent process, unconnected with changes in the surrounding parts, and was also not secondary to a preceding thrombosis. The results of this phlebitis obliterans shewed itself in all three cases in the same manner : namely, congestion hyperæmia, atrophy, and induration of the liver, with congestion of the portal veins and a resulting fatal ascites. The thrombus which was found in the hepatic veins in all three cases, as also the thrombosis of the portal vein in the second case, I consider to be secondary to the phlebitis of the hepatic veins and to be brought about by the disturbance of the circulation in these veins. Nevertheless the secondary thrombosis was certainly of very great importance as leading to a disturbance of the circulation which became so severe that compensation by collateral circulation became inadequate, and a high degree of ascites developed. 
In accordance with what has been said I do not hesitate to say that this independent phlebitis obliterans of the main trunk of the hepatic vein is a disease sui generis. With regard to its ætiology I have already pointed out that the phlebitis probably arises on a syphilitic basis and consequently should belong to the same category of circulatory lesions as syphilitic endarteritis obliterans of the cerebral vessels. Naturally further observations are necessary to confirm this.

Without detracting from the value of Chiari's histological findings it must be admitted, as other writers have pointed out, that the evidence of syphilis in all his cases is slender and unconvincing.

Some thirty cases have been described since Chiari's classical description, but we must limit our observations to those that have features in common with our own.

Previously recorded cases in childhood.-We have been able to trace records of six cases occurring in childhood. $\mathrm{Gee}^{3}(1871)$ was the first to describe such a case, the patient being a male child, 17 months old, with a three months' history. Lazarus-Barlow ${ }^{4}(1899)$ recorded the case of a boy of 13 years of age,

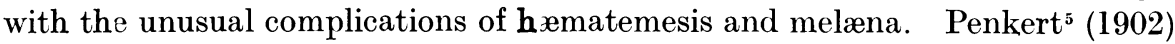
described the condition in a male child, 22 months old, whose abdomen had been distended from birth. Theodore Fisher's ${ }^{6}$ case (1902) was a girl of 3 years of age ; Fabris' ${ }^{7}$ case (1905) a male of 16 years of age ; and Hess's ${ }^{8}$ case (1905) a girl of 16 years of age. The usual indication of disease in these cases was a swelling of the abdomen, attributed to ascites. Details of these cases are given in Appendix A.

Cases in which carcinoma of the liver supervened.--In 1918 Nishikawa ${ }^{9}$ gave an excellent description of ten cases of primary occlusion of the hepatic veins. No less than four of these developed carcinoma of the liver, which he regarded as secondary to the parenchymatous regeneration in peri-portal areas. The cells of the carcinoma arose from the liver cells. Such a malignant neoplastic process is of course well known as arising secondarily to compensatory proliferation of the liver cells in hepatic cirrhosis due to other causes. There may be more than one focus of malignant transformation. Rosenblatt ${ }^{10}$ in 1867, and Eppinger ${ }^{11}$ in 1876, also described cases of hepatic vein occlusion, cirrhosis of liver, and carcinoma, but we have been unable to secure an adequate description of Eppinger's case. Synopses of these cases are given in Appendix B.

Previous cases without ascites.-The absence of ascites in our case must be considered a very unusual feature. We have been able to trace only two othərs whəre ascites was absent, both described by Nishikawa. In one, Casè 8 of his series, as in ours, carcinoma supervened and it has therefore been included in the previous section. The other (Case 3) was of interest in that there was great varicosity of the osophageal veins and a fatal oesophageal hæmorrhage. A slight degree of ascites was found at autopsy but was not recognized during life. The majority of patients with occluded hepatic veins die from the recurrent ascites and odema. Of the three cases without ascites (our own case and the two of Nishikawa), two died of carcinoma and one of hæmatemesis. 
Nishikawa ${ }^{5}$ (Case 3 of his series).-Male, aged 31. Five months before death the patient developed œedema of the lower limbs. A few weeks later he noticed dilatation of the veins of the abdomen, and a swelling in the epigastric region. He complained of general malaise and epigastric discomfort. After one month the dilated veins increased, and following this the œdema became less although it never quite disappeared. The liver was felt to be enlarged but there was no ascites. A few days before death the patient vomited $250 \mathrm{c.cm}$. of blood. A clinical diagnosis of obstruction of the inferior vena cava and hepatic veins was made. At autopsy the clinical diagnosis was confirmed, the inferior vena cava being obliterated for a distance of $1 \mathrm{~cm}$. near the diaphragmatic opening, and both hepatic veins being similarly obliterated at the site of their entrance to the cava. There was extensive diaphragmatic collateral circulation, well developed abnormal accessory liver veins, and multiple ruptures of varicose œesophageal veins. The liver showed a high degree of ' congestion cirrhosis.' There was a slight amount of ascites which was thought to have occurred just before death. The fact that a fatal rupture of œsophageal veins occurred in the absence of clinically diagnosable ascites, was considered of great interest. Nishikawa points out that Sascer found that in 200 cases of cirrhosis of the liver only three died of œsophageal bleeding unaccompanied by ascites.

\section{General clinical features of the disease.}

Although usually occurring before the age of forty the disease may manifest itself at all ages, and is found in both sexes. The majority of the cases in early life were in males. The onset may be acute or insidious, and the duration from a few days to many years. The liver is generally enlarged to palpation and its surface may be nodular. In acute cases it may be very tender. Ascites is nearly always present and is often associated with cedema of the legs, which, however, rarely precedes the assites. The œdema depends upon the extent of involvement of the inferior vena cava. Dilatation of the superficial veins over the upper abdomen and chest wall is an important diagnostic sign. Jaundice rarely occurs. Symptoms are often indefinite especially in the early stages. Stabbing pains in the right hypochondrium and vague dyspepsia, with or without vomiting, may be complained of. Acute cases have been mistaken for poisoning or intestinal obstruction. In cases followed over a number of years it is possible to trace definite stages in the development of the disease. Thus the first sign may be a large liver, at a later date dilated superficial veins appear, and finally ascites; or the number and extent of the superficial venous anastomoses may increase at definite intervals; or a transient ascites may precede the terminal one by some years. Such incidents are probably due to successive occlusion of hepatic veins, which are compensated for by further anastomoses or possibly by canalization of older organized thrombi.

Usually the ascites recurs in spite of repeated paracentesis, death following within a few months. Carcinoma of the liver, with or without metastases, hæmatemesis due to rupture of varicose osophageal veins, coma from hepatic insufficiency, or some intercurrent affection may be the immediate cause of death.

Cirrhosis of the liver, tuberculous peritonitis and carcinomatosis are the conditions which chiefly simulate the disease. 


\section{Pathological results of hepatic vein obstruction.}

1. Collateral circulation.-The degree of collateral circulation depends upon the amount of obstruction in the hepatic veins, or in the vena cava at or above the junction of the hepatic veins. If the collateral circulation is adequate there may be no signs of disease, or at least no ascites, but sooner or later in most cases it breaks down. The most important collateral circulation takes place through the diaphragmatic veins and the accessory liver veins. In all cases numerous dilated and tortuous veins form plexuses on both sides of the diaphragm, and are a very characteristic feature at autopsy. Superficial cutaneous plexuses are also present in many cases. Less important compensation is evidenced by varicosity of the œsophageal and hæmorrhoidal veins.

2. Congestion and fibrosis of liver-A description of the liver in several cases has already been given, so that the following is but a brief summary:-The intralobular and sublobular veins are grossly distended. The nature of the occlusion of the hepatic veins varies and is discussed in the section on rtiology. The changes in the liver itself are not constant. In the central acinous zone the parenchymatous cells are usually atrophied and sometimes entirely disappear. In their place there is a proliferation of connective tissue. The fibrosis of the atrophied areas is considerably greater than that which is usually found in cases of chronic heart failure. The fibrosis may extend to the portal areas. The atrophy of the liver cells in the central zone is partly ascribed to lack of nutrition and partly to pressure of congestion. The liver cells in the peripheral acinous zones are in most cases intact and often hypertrophied. These cells show evidence of regeneration, which is sometimes slight but usually well marked. In a few cases the proliferation may become atypical and progress to carcinoma.

\section{Aetiology.}

(1). Endophlebitis. - The term endophlebitis is used to indicate a primary inflammation of the vein with or without secondary thrombosis. In discussing Chiari's cases it was pointed out that he interpreted the histological findings as indicating an endophlebitis and not a thrombophlebitis. ' In every case it was an entirely independent process unconnected with changes in the surrounding parts and also not secondary to a preceding thrombosis.' Even if syphilis can be accepted as a carse of the endophlebitis in any of Chiari's three cases, there has rarely been any evidence of syphilis in subsequent cases. Nishikawa, in reviewing the literature, states that "syphilis is without doubt a causal component but that the development of this disease is by means of a primary endophlebitic process must be denied.'

A case of endophlebitis of particular interest was described by $\mathrm{Ohno}^{12}$ in 1921. There the histological picture was thought clearly to indicate a primary endophlebitis. 'All the liver veins, from the largest to the smallest showed intimal thickenings. In the intima, media, and adventitia, one saw in places a few lymphocytes, round cells, and plasma cells. The thrombi (seen at the junctions of hepatic veins) were fresh and not organized (as in other published 
cases). There was a general diffuse thickening of the intima. The walls of the veins were so thickened that the lumen appeared to be almost stenosed. Complete obliteration however could not be made out, and organized thrombi were not found anywhere. There was a well-marked diaphragmatic collateral circulation.'

Ohno ${ }^{12}$ considered the histological picture to be one of diffuse chronic phlebitis and to furnish a sure proof of a primary phlebitic disease (endophlebitis). He suggested that it is only in such early cases that it is possible to differentiate thrombophlebitis and endophlebitis.

Hess $^{8}$ in 1905 describing the case of a girl of 16 , in whom the autopsy was performed by Chiari, was of opinion that the histological examination indicated a chronic inflammation of the veins or primary endophlebitis. No blood pigment was found in the connecting tissue obliterating the lumen of the veins.

(2). Thrombophlebitis. - This term is used to indicate a primary thrombosis with secondary changes in the vein wall. In 1912 Thompson and Turnbull ${ }^{13}$ described two cases and put forward important histological evidence in favour of this ætiology of hepatic vein occlusion. The character of the tissues, their great vascularity, the position and sharp demarcation of the lesions suggested thrombophlebitis. To explain the site of the thrombosis the authors pointed out that at the diaphragmatic openings of the inferior vena cava there must frequently be retardation or even reversal of the blood stream consequent upon increas of pressure within the thorax; the ostia of the hepatic veins where the two blood streams meet with that of the inferior vena are positions in which eddies are liable to occur. Sharply defined projections of the intima are interpreted as organization of thrombi which have been silted up at the junction of converging streams of blood. Thompson and Turnbull nevertheless add that: 'Although as indicated above the ostia of the hepatic veins into the inferior vena cava would appear to be sites peculiarly favourable to the formation of thrombi, yet routine examination in a very large number of autopsies has shewn that the occurrence of such thrombi is of extreme rarity.' The possible influence of infection is considered and it is pointed out that in two cases (those of Chiari ${ }^{2}$ and Craven Moore ${ }^{16}$ ) symptoms followed two months and three years after pregnancy.

Aschoff $^{14}$ in 1912 discussed the deposition of agglutinated red cells, leucocytes, bacteria, and fibrin, on the intima of veins at the sites of constriction or widening, or at the confluence of blood-streams. This offers a further explanation of the site of thrombosis.

In 1918, Nishikawa concluded from a histological examination of ten cases that thrombophlebitis is the essential lesion. He uses the term, however, somewhat comprehensively so as to include primary endophlebitis. After considering the possible initial influence of infections, toxins, etc., he states ' I use the expression thrombophlebitis with regard to the disease not in the strict sense, but only as an expression which has come into general use. It is meant to include thrombophlebitis properly so-called (secondary phlebitis) and phlebitic thrombosis (in which the thrombosis is secondary).' 
(3). Mechanical hypothesis.-In 1900, Kretz ${ }^{15}$ explained the occlusion of hepatic veins on mechanical grounds. He pointed out that if the liver veins were closed for some distance, the obliteration was always oldest at the junction and most recent peripherally. The site first affected is thus the meeting point of a lesser and greater stream of blood. The intra-abdominal pressure and the hepatic ligaments help to keep the liver in position, but nevertheless the liver is to some extent suspended by the junction of the hepatic veins with the vena cava. It is thus possible for stress and strain to result in mechanical damage to the intima. The exuberant scar tissue may result in occlusion of the ostia of the hepatic veins. Such factors as violent coughing, jumping, etc., may thus be responsible. Nishikawa ${ }^{9}$ suggested that if Kretz's hypothesis were right, the condition would occur more frequently, and especially with cases of abdominal ptosis. Kretz himself, however, does not deny the additional influence of infection, toxins, or even increased coagualability of the blood in the hepatic veins.

(4). Congenital hypotheses.--Rosenblatt ${ }^{10}$ in 1867 first suggested a congenital origin. He did not, however, mean a congenital malformation, but postulated a foetal interstitial hepatitis as the primary condition with secoondary occlusion of the hepatic veins. In his case the inferior vena cava passed through the liver fissure without receiving any branches from the liver parenchyma, but its inner walls showed light ridges and depressions as it passed through the diaphragm.

In the case described by Gee already referred to, the hepatic veins ended abruptly just short of the vena cava, being cut off from it by a thin membrane only. The lining membrane of the cava was perfectly smooth and natural, but where the mouths of the hepatic veins should have been, there were shallow dimples, which had not at all the look of scars. In considering congenital malformation, Gee wrote "The liver may have been originally malformed so that the hepatic veins never did enter the vena cava; the cirrhosis which was undoubtedly present to a small degree being due to chronic congestion, which was manifested at last by the dropsy.' Gee, however, was unable to explain the closure of the ductus venosus, or the dimples in the vena cava which might indicate where the mouths of the hepatic veins had apparently once been. He therefore suggests an alternative explanation of primary cirrhosis of liver with secondary occlusion of the hepatic veins.

Fisher ${ }^{6}$ in 1902 described the cas of a girl, aged 3, where the cirrhosis was only very slight in extent; and in the same year Penkert discussed the case of a 2.2 months old child where swelling of the abdomen had been present from birth. The umbilical vein remained patent although the ductus venosus was closed. Penkert did not consider the latter fact to exclude a congenital origin although he gave no valid reason for so thinking. He concluded that the clinical and histological picture strongly supported a congenital ætiology and stated that ' a congenital malformation in my case is undoubted.'

In $1902{ }^{16}$ Craven Moore suggested a congenital susceptibility to obliteration. 'With the cessation of the placental circulation the ductus venosus which opens into the vicinity of the terminal portion of the right hepatic vein 
becomes obliterated. This tendency to obliteration may persist in the immediate neighbourhood and may be recalled into activity by some irritant which would ordinarily remain without morbid manifestations.' Rolleston ${ }^{17}$ put forward a similar view in commenting on Hoover's cases in 1920 : "There may be a very remarkable lesion, viz., cicatricial contracture of the orifices of the veins and this may occur extremely early in life as in the case recorded by the late Dr. Gee. Possibly it is due to an extension of the process of obliteration of the ductus venosus, comparable to the excessive process described by Bland-Sutton as occurring at the site of the duct of Meckel's diverticulum in connection with the small intestine.'

In 1905 Fabris? described the case of a 16 year old boy where 'there was a rare form of atresia of the large liver veins at their junction with the inferior vena cava, which apparently is of congenital origin resulting from abnormal development.'

In 1918 Nishikawa $^{9}$, although not favouring the hypothesis of congenital malformation, observed that rudimentary congenital valves in the inferior vena cava sometimes occur in these cases and may be a factor in producing thrombosis.

With several cases occurring in the earliest years of life it is very natural that a congenital origin should have been suspected. Against this is the fact that many cases have occurred in the thirties and forties and occasionally even later, but this objection could also be put forward in such conditions as cervical rib and congenital cystic kidney. Certainly in the case of occlusion of the hepatic veins we know that there is a well-marked compensatory diaphragmatic venous anastomosis, and it is only when this breaks down that signs and symptoms manifest themselves.

More fundamental objections to the suggestion of a congenital malformation have been raised by several investigators which have constituted a stumbling-block to its acceptance, but we do not believe that these objections can be sustained. The chief point brought forward against congenital malformation is the failure of the ductus venosus to remain patent in those cases where the liver veins are not connected with the inferior vena cava. Although on first consideration this appears to be a logical objection, it fails to consider the result should the ductus venosus persist. From a teleological point of view this would be disastrous, as the liver would thereby be cut out of the circulation. It is much more reasonable to expect a compensatory anastomosis on both sides of the diaphragm, thus conveying the blood from the liver by a somewhat tortuous course which avoids the points of obstruction. This is exactly what is found in all cases.

Another objection to the hypothesis of congenital malformation is the presence of dimples at a situation where the hepatic veins usually join the inferior vena cava. These are interpreted as proof of the fact that the hepatic veins did originally join the inferior vena cava, and that they have become discontinuous through subsequent organizing thrombosis or perhaps even as a result of cirrhosis. There is, however, another possible explanation which would support the congenital hypothesis. It may well be that the normal intra-uterine 
process of obliterating many of the venæ revehentes has progressed too far, and has failed to leave patent the two hepatic veins at their junction with the cava. The presence of dimples cannot therefore be considered as contradicting the hypothesis of congenital malformation, and in support of this contention Professor W. Wright has kindly sent us the following explanatory note :-

The course of the vitelline veins to the sinus venosus becomes interrupted with the formation of the liver and in consequence we get venæ advehentes leading to the liver, large blood spaces in the liver termed sinusoids, and venæ revehentes taking the blood from the liver to the sinus venosus. Prior to entering the liver the vitelline veins of either side are connected by the transverse channels. A vessel, the ductus venosus, soon makes its appearance running from the most proximal of these channels to the venæ revehentes of the right side. This vessel increases to such an extent that the right venæ revehentes by comparison appear to ke mere tributaries. Later the vessel is joined by the corresponding venæ revehentes of the left side, with the result that we have a single vessel opening into the sinus venosus and receiving the venæ revehentes, which now become known as the hepatic veins. Immediately after birth the portion of the ductus venosus caudal to the openings of the hepatic veins becomes obliterated, the portion remaining becoming the upper or terminal part of the inferior vena cava. With such vascular changes variations may easily occur and certain of the hepatic veins may either fail to acquire, or may lose their connection with, the inferior vena cava.

It has also been observed (Thompson and Turnbull ${ }^{13}$ ) that the coats of the veins at the site of the obstructions are fully developed. Although this does not support a congenital ætiology, it is not necessarily a fundamental objection to it.

A further positive consideration in favour of a congenital origin is the fact that the site of obstruction is the meeting point of three venous channels, the hepatic veins, inferior vena cava, and ductus venosus, the last of which itself becomes obliterated up to the junction. On embryological grounds, therefore, a congenital stricture at this point would by no means constitute an unexpected congenital malformation.

Conclusions.- It is possible that primary occlusion of the hepatic veins may have several causes; on the other hand some of the hypotheses of ætiology are not incompatible with one another. In many autopsies there is histological evidence of the presence of thrombi at various stages of organization. This suggests that thrombi have been deposited at different intervals during life. These findings are in keeping with the clinical histories in several cases. Thus we have seen that the disease may go on for a considerable time and its course be punctuated by episodes which can only be explained by further obstruction to the hepatic circulation, e.g., the sudden appearance of dilated epigastric veins with further extension at a later date, transitory ascites, or sudden pain and enlargement of the liver. Whatever the initial cause of the condition it is reasonable to suppose, especially in view of post-mortem findings, that these exacerbations are due to superimposed thrombosis, and that a possible recovery from them depends upon the evolution of additional compensatory venous channels. As to the immediate cause of these successive thromboses, one can only guess at such factors as toxins, infections, and even mechanical causes as suggested by Kretz. In some cases pregnancy, influenza, and whooping cough, have been known to precede the appearance of symptoms, although it is obviously difficult to say that these were really causal factors. 
The acceptance of the occurrence and repetition of thrombosis is perhaps more important than the question whether there is initial inflammation of the wall of the vein. Although in most cases it would appear that no chronic inflammation of the intima, has preceded the thrombosis, it is not an easy histological problem to decide whether toxins, or infections, have affected the intima immediately prior to the deposition of a thrombus. Even more must this be the case when the thrombus is partly or completely organized, and the intima is secondarily affected. It has been seen that Nishikawa after a very extensive experience of the disease decided to use the term 'thrombophlebitis' so as to include both primary thrombosis and primary inflammation of the vein. It must be admitted, however, that in some cases (Thompson and Turnbull ${ }^{13}$ ) all the histological evidence is in favour of an apparently primary thrombosis.

Whatever view is taken as to the immediate cause of the recurring thrombosis, it still remains to account for the site of the lesion. Thrombosis at the junction of the hepatic veins is a great rarity in post-mortem examinations, and in these cases therefore it is reasonable to assume some primary predisposing factor. We are inclined to accept a congenital malformation as a possible explanation, especially when death occurs in early childhood, or when manifestations can be traced back to that period of life. The stasis resulting from complete obliteration or narrowing of veins would constitute an important factor in favouring subsequent recurrent thrombosis.

\section{Summary.}

1. A case of occlusion of the hepatic veins with cirrhosis, which began in early childhood and terminated 23 years later in primary carcinoma of the liver, is described.

2. A full account of the appearances found after death is appended.

3. The history of the condition is given with a summary (a) of cases previously recorded in childhood, (b) of those in which carcinoma of the liver supervened and (c) of those which resembled the present case in having no ascites.

4. The general clinical features are outlined and the hypotheses of causation indicated and discussed.

We are greatly indebted to Professor H. M. Turnbull for the pathological report on our case, although he is naturally not responsible for the views we have put forward; and to Professor W. Wright for his valuable help with the embryological aspects.

\section{REFERENCES.}

1. Budd, Diseases of the Liver, 1857, 184.

2. Chiari, H., Ziegler Beit, z. path. Anat., Jena, 1899, XXVI, 1.

3. Gee, S. J., St. Bart. Hosp. Rep., Lond., 1871, VII, 141.

4. Lazarus-Barlow, W. S., Trans. Path. Soc. Lond., Lond., 1899, L, 146.

5. Penkert, M., Virch. Arch.f. path. Anat. Berlin, 1902, CLXIX, 337.

6. Fisher, T., Jiristol Med.-chir. J., Bristol, 1902, XX, 209.

7. Fabris, A., Centralb. f. allg. path. u. path. Anat., 1905, XVI, 709. 
8. Hess, A. F., Amer. J. Med. Sci., Philad., 1905, CXXX, 986.

9. Nishikawa, Y., Med. Fak. D.K. Jap. Univ., 1918, XX, 151.

10. Rosenblatt, O., Virch. Jahr. der med., Berlin, 1867, I, 226.

11. Eppinger, Prag. Med. Woch., 1879, 39, 40.

12. Ohno, S., Mikerl. Med. Fak. Univ. Tokio, 1921, XXVII, 215.

13. Thompson, T., \& Turnbull, H. M., Quart. J. Med., Oxf., 1912, V, 277.

14. Aschoff, E., quoted by Nishikawa (loc. cit.).

15. Kretz., R., Egeb. des allg. Path. u. path. Anat., 1902, Jg. VIII., Abtl. II, 498.

16. Moore, F. C., quoted by Thompson and Turnbull (loc. cit.).

17. Turnbull, H. M., Proc. R. Soc. Med., Lond., 1917, X, (Gen. Rep.), 47.

\section{APPENDIX A.}

\section{Previously recorded cases in childhood.}

$\mathrm{GEE}^{3}$ (1871).-Male child, 17 months of age who had had no illness until 14 months old, when he seemed to have pain in his belly, and his whole body swelled. In 2 days the swelling disappeared from the rest of the body and settled in the abdomen. When 16 months old the abdomen was tapped and $12 \mathrm{oz}$. of greenish serum were let out. The next day 2 pints were drawn off, and 3 weeks later 2 pints more. Five days after this he died.

Autopsy.-Liver a little smaller than usual; dense, tough and with thick round edges. Slightly nodular surface. Thickened capsule. Section of liver showed nutmeg appearance. The liver was congested, indurated, and fatty. The hepatic veins ended abruptly just short of the vena cava, being cut off from it by a thin membrane only. The lining membrane of the cava was perfectly smooth and natural, but where the mouths of the hepatic veins should have been, there were shallow dimples which had not at all the look of scars. Many of the larger branches of the hepatic veins were filled by tough colourless adherent thrombi. Extensive anastomosis of veins on both surfaces of diaphragm. Ductus venosus closed. Spleen natural size and rather tough. There was no description of the microscopic changes.

Lazarus-Barlow 4 (1899).--Male, aged 13. Four months before death the abdomen began to swell, the patient became languid and dyspnœic, and hæmatemesis and melæna occurred. He was a thin, slightly jaundiced boy, with gross ascites, a plexus of distended veins over the abdomen and distended venules on the cheeks. The edge of the liver was felt 3 finger-breadths below the costal margin. With regard to the question of syphilis, the evidence available was (i) that the mother had no miscarriages up to this, the 3rd child, but four afterwards ; (ii) the histological character of the hepatic fibrosis. No alcoholic history. Paracentesis was performed twice (12 pints on each occasion). The patient gradually sank after the second paracentesis.

Autopsy.-Localized suppurative peritonitis. The liver, which weighed $2 \mathrm{lb} .10 \mathrm{oz}$., was granular, and mottled on the surface. On the upper aspect posteriorly was a large mass of cicatricial tissue which extended $1 \frac{1}{2}$ in. into the depth of the organ and involved the hepatic vein. Numerous branches of the hepatic vein, both large and small, were occluded by partially adherent and decolorized thrombus. The cicatricial mass suggested a former gummatous condition, and its edges shade $d$ off in the form of trabeculæ of fibrous tissue into the (macroscopically) normal substance of the liver. At the same time the branches of the portal vein served as centres of a fibrous tissue overgrowth throughout the organ, so that a section revealed macroscopically a mottled surface in which foci of what appeared to be normal liver substance were separated by irregular trabeculæ of fibrous tissue, which stretched in all directions. Here and there were seen sections of the occluded hepatic vein. Microscopically the liver, even in its apparently most nearly normal regions, showed the existence of a mixed fibrosis. The greater part was of the multi-lobular variety, but there was much of the intercellular type. None of the white masses in the liver was found to be gummatous. 
Penkert $^{5}$ (1902).-Male, 22 months old, bottle-fed. History of whooping cough in the summer of preceding year. When 18 months old he could walk, but soon went off his feet. Since birth his abdomen appeared to be distended, but this increased markedly a few weeks before admission. At the beginning of April, 1902, dyspnœa was noticed. On examination he appeared to be a well-nourished, well-developed child, but somewhat anæmic. The abdomen was distended, and the umbilicus prominent. On the right side of the abdomen the liver could be felt enlarged and with a sharp edge reaching to the level of the umbilicus. Ascites and œdema of the abdominal wall were present. Urine normal. April 10th, 3 litres of clear yellow fluid of specific gravity 1011, and containing a large quantity of albumin drawn off. Dilated veins formed a caput medusæ round the umbilicus. A few days later another 3 litres were with. drawi. April 30th. : gross cedema of legs. A tentative diagnosis of congenital syphilis was made. On May 1st the abdomen was opened and much fluid was found. Liver enlarged to level of umbilicus, soft, smooth, congested. The spleen moderately enlarged. The Talma operation for draining the ascites was performed. A small piece of liver was taken for section and showed some atrophy and pigmentation. Liver acini not clearly seen, peripheral fat infiltration, marked dilatation of central veins. Thickening of peripheral connective tissue. Much congestion. A further tentative diagnosis of congenital heart lesion was then made. The child died on 3rd May.

Autopsy.-The liver was greatly enlarged. It had a sharp edge and bluish red surface. It was intensely congested. The left edge was definitely granular. The live: was soft and the capsule not thickened. The whole picture was that of severe congestion with parenchymatous atrophy. The cut section (after squeezing out the blood) was so spongy as to give the appearance of a cavernous angioma. There were hardly any clearly preserved acini. There was thickening of the connective tissue round the portal veins in the left lobe. Microscopic section of the liver showed great congestion, the central veins being much dilated and filled with blood. Between these were atrophied liver cells and bile pigment. There was periportal connective tissue surrounded by atrophied liver cells and fatty infiltration. 'In the left lobe there is nothing more left of the acinous structure. Here we have the distinct picture of a cirrhosis.' The spleen was somewhat enlarged and congested and showed small distinct follicles.

Heart and kidneys were normal. The inferior vena cava was somewhat twisted. The hepatic veins were indistinct. The lumen was only large enough to permit the passage of a hairlike probe and in the right vein there was a thrombus. The venules were obliterated, or almost filled with fibrous clot. Below the obstruction the hepatic veins were greatly distended but the majority were closed by thrombi. The wall of the vena cava was thickened. The umbilical vein permitted a small bristle to pass through it. The ductus venosus was closed.

FisheR $^{6}$ (1902).-Girl, aged 3. Seven months before death patient had an attack of whooping cough. For three months there had been swelling of the abdomen. On examination, several dilated superficial veins were seen in the upper abdomen and chest. There was marked ascites. The liver was enlarged four finger-breadths below the costal margin. The condition was thought to be due to cirrhosis. There was no evidence of syphilis. Paracentesis (65 oz.) was followed by rapid reaccumulation of fluid.

Autopsy.--The hepatic veins were found to be blocked by thrombi in varying degrees of organization. Both hepatic veins, where they should have opened into the vena cava, were found to be completely occluded. A small fibroid nodule marked the site of entrance of one hepatic vein into the inferior vena cava and a small depression the size of a pin's hexd that of the other. The walls of the hepatic veins were thickened but Fisher thought this might have been secondary to the thrombosis. The cirrhosis of the liver was only slight in extent.

FABRIS $^{7}$ (1905).-Male, age 16. This case is described as one of a rare form of atresia of the large liver veins at their juncture with the inferior vena cava which apparently is of congenital origin, resulting from abnormal development. Thrombosis of the intra-hepatic veins enisued, and following this there were special structural changes of the liver quite different from the usual passive congestion. (This summary is taken from an extract as we were unable to obtain the original paper). 
Hess $^{8}$ (1905).-Girl, age 16. Four years previously she had been in hospital, suffering from dyspnœa and abdominal distension. Ascites was present but after 6 months' treatment by repeated paracentesis and diuretics it disappeared entirely. She was discharged with the diagnosis of hypertrophic cirrhosis of the liver, and remained quite well for nearly four years. On October 1st, 1904, 6 weeks before death, she began to have abdominal pain, and within 3 days marked swelling of the abdomen and distension of the veins of the upper abdominal wall appeared. Ascites was present, the liver was palpable $2 \mathrm{~cm}$. below the costal margin and the spleen $1 \mathrm{~cm}$. below the ribs, dilated veins were present over the abdomen and chest; there was no œdema of the lower extremities.

Autopsy.-The patient died on November 13th and Professor Chiari performed the autopsy. No patent branches of the hepatic veins were apparent near the vena cava, but, instead, what seemed to be obliterated veins. The intra-hepatic portion of the vena cava was remarkable in that no ostia of the hepatic veins were visible on its inner surface. The ductus venosus was obliterated. Microscopically the obliterated hepatic veins could be traced into the parenchyma, in some segments for 2 to $3 \mathrm{~cm}$., extending from the vena cava as firm gray bands, without a lumen. The vena cava in the posterior surface of the liver shewed four minute ostia, ranging from a pinpoint to a pinhead in size. The connective tissue obliterating the lumen of the veins shewed no pigment. The liver was of the cirrhotic granular type with characteristic atrophy and regeneration.

\section{APPENDIX B.}

\section{Previously recorded cases in which carcinoma supervened.}

Rosenblatt $^{10}$ (1867).-Male, 27 years old, admitted to hospital June 12th, 1867. Was apparently well until 7 weeks before admission, when he noticed a gradual swelling of the abdomen, with occasional generalized abdominal pains. His appetite became poor but thirst was increased. There was no marked fever. There was a history of paracentesis abdominis before admission, but the abdomen continued to swell, and there was œdeman of the scrotum and lower extremities. Latterly the patient suffered from dyspnœa. There was no history of alcohol. On admission there was considerable ascites and the size of the liver could not be ascertained. There was tortuosity of the superficial abdominal veins. No albuminuria. The diagnosis was malignant or tuberculous ascites, and after repeated tappings the patient died on July 16 th.

Autopsy.-The peritoneum was full of nodules which on microscopic section shewed alveolar carcinoma. In the right lobe of the liver there was a carcinomatous nodule the size of a goose's egg, which had become adherent to the hepatic flexure of the colon. A few nodules were present in the liver capsule. The left lobe of the liver was connected to the stomach wall by connective tissue containing numerous blood vessels. The veins from the stomach appeared to join the internal mammary veins on the other side of the diaphragm. There were adhesions from the liver to the diaphragm. There was an unusual and abundant venous anastomosis below the diaphragm. The portal vein appeared normal. The inferior vena cava passed through the liver furrow without receiving any branches from the liver parenchyma. Its inner walls shewed light ridges and depressions as it passed through the diaphragm. There was a partial cirrhosis of the liver. No microscopic description.

Nishikawa ${ }^{9}$ (1918). (Case 4 of his series).-Male aged 26. While at school patient was said to have had swelling of the epigastrium and great impairment of appetite. When 23 years old he suffered from gastro-intestinal disturbances, swollen abdomen, diarrhœea, and fever. Following this there developed a pleurisy of the right side from which he recovered in two months. At that time an enlargement of the spleen was observed. One year before his death there was pronounced œdema of the legs which disappeared after a few days. His abdomen gradually became swollen. The œdema of the legs recurred 9 months before death and persisted. When the patient entered hospital, the subcutaneous veins in the anterior abdominal wall were dilated, the thoraco-epigastric and median xiphoid veins being varicose. Abdominal paracentesis was performed eleven times. At autopsy obliteration of the hepatic veins and of the inferior 
vena cava was found. The latter was completely stenosed directly above the entrance of the liver veins by an organizing thrombus. Old and adherent, as well as fresh, thrombi were present in numerous liver veins. The ostia of the latter were occluded by fibrous tissue. The liver surface was uneven, irregular, and coarsely granular. On the posterior surface of the right lobe there was a prominent round nodule, the size of a pea which on section was seen to be of a marrow-like consistency and yellow-white in colour. Microscopically this nodule was of cancerous nature, arising from the liver parenchyma. The rest of the liver shewed 'congestion induration' with increase of connective tissue round the hepatic and sublobular veins. The liver cells in the centre of the lobules were atrophied but those in the peripheral acinous zone were unaffected, often hypertrophied, and proliferating.

Nishikawa (Case 5 of series).-Female, aged 34. For 10 years she had noticed recurrent transitory attacks of œdema of the legs and abdominal distension. This was probably associated with enlargement of the liver, as from the first a diagnosis of hepatic disease was made. At 26 years of age, marked dilatation of the subcutaneous veins of the abdomen was observed. A note states that when she was 32 the liver was felt after paracentesis to extend 3 finger-breadths below the costal margin. The surface was rough and the edge firm. A clinical diagnosis of obstruction of the intra-hepatic portion of the inferior vena cava was made. In spite of repeated paracentesis the ascites and also the œedema of the legs persisted for 18 months, the patient dying in January, 1915.

Autopsy.-The hepatic veins were obliterated at their openings into the vena cava, and there was marked stenosis of the latter as it passed through the diaphragm. The hepatic veins were thickened, and in places filled with thrombi. The inferior vena cava was almost completely obliterated by a fibrous mass for $1 \frac{1}{2} \mathrm{~cm}$. The liver was granular and nodulated, the left lobe being markedly atrophied. The largest nodule was the size of a fist and was situated in the middle of the right lobe. It was greyish yellow, soft, and degenerated. Microscopically, the liver shewed the characteristic picture of 'congestion induration.' There was atrophy of the central parenchyma with hypertrophy and knotty hyperplasia of the peripheral acinous zone. Nishikawa concluded that 'the patient died of the intercurrent affection, parenchymatous liver cancer, which, unlike the former case (Case 4) reached an enormous size and was widely metastasized intra-hepatically as well as in other organs. With regard to its genesis it is to be regarded as secondary to a cirrhotic regenerative process. Finally, it must be emphasized that the cancer nodules were not present in the direct neighbourhood of the site of obliteration and consequently stood in no causal relationship to the closing up process.'

Nishikawa (Case 8 of series).-Female, age 38. Eighteen months before death the patient accidentally discovered a painless tumour, the size of a pigeon's egg, in the right hypochondrium. This gradually increased in size. Two months before death she complained of epigastric pain and loss of appetite, and was thought to have carcinoma of the stomach. On examination in hospital the liver was palpable 3 finger-breadths above the umbilicus in the median line. The surface of the liver was granular and a tumour was palpable in the right lobe. The clinical diagnosis was carcinoma of the liver. There was no œdema or ascites.

Autopsy.-The hepatic veins were found to be obliterated at their entrance to the vena cava. The interior of the latter was thickened and the lumen occluded just below this point. Adhesive thrombi were present in the hepatic veins. The liver surface was grossly irregular and contained several carcinomatous nodules. The left lobe was much atrophied and on its posterior surface were two tumours the size of a goose's egg. In the middle of the anterior edge of the right lobe was another tumour the size of a child's head. Microscopically the liver showed typical congestion cirrhosis. Hyperplasia and regeneration were, however, much less marked than in Cases 4 and 5. Metastatic cancer nodules were present in both lungs. Nishikawa considered the cancer to be a parenchymatous liver cancer. In view of the well marked collateral circulation, the absence of ascites, and the moderate degree of cirrhosis, he concluded that the patient might have lived many years but for the intercurrent cancer.

Nishikawa (Case 10 in series).-Male, age 28. Patient had noticed dilatation of the superficial abdominal veins at the age of 15 . At the age of 22 , he suffered from dyspnœa, palpitation, and œdema of the legs after slight exertion. There was also some cyanosis of the lips. At 24 there was some dilatation of the superficial epigastric veins. Three months kofore 
death he vomited one litre of brownish fluid (? blood, ? wine). Five days later he suffered from marked dyspnœa and palpitation. At that time he was pallid and wasted. The superficial veins of the chest, abdomen, and back were enlarged and tortuous. (Edema of the legs was present, and the abdomen greatly distended. After paracentesis, a hard nodular tender tumour was felt in the epigastrium. In the right mammary line the liver edge was felt under the costal margin on deep inspiration. The spleen was not palpable. Paracentesis was performed four times in one month. Nausea and vomiting occurred, and he gradually wasted and fell into a terminal coma

Autopsy.-There was complete obliteration of all the principal liver veins at the point where they join the inferior vena cava, and occlusion of the inferior vena cava below this. The latter was completely closed below the hepatic vein ostia. The intima was generally thickened and there was a valve-like formation which was considered congenital. The hepatic veins showed fibrous occlusion and recanalization. A proliferating warty mitral endocarditis complicated the post-mortem picture. The liver surface was coarsely nodular and irregular, and several greyish white tumour nodules up to the size of a hen's egg could be seen. Microscopic examination showed characteristic ' congestion cirrhosis,' with atrophy of the central acinous zone, and hypertrophy and regeneration of the peripheral liver parenchyma. An atypical proliferation was regarded as the precursor of the carcinomatous nodules in the liver. Metastases of the parenchymatous liver cancer were present in the gall bladder. 